\title{
Editorial to selected papers from the 5th International Conference IMEKO TC16
}

\author{
Jorge C. Torres-Guzman ${ }^{1}$, Tokihiko Kobata ${ }^{2}$ \\ ${ }^{1}$ Centro Nacional de Metrología, Queretaro, Mexico. \\ ${ }^{2}$ National Metrology Institute of Japan (NMIJ) Tsukuba, Japan
}

Section: EDITORIAL

Citation: Jorge C. Torres-Guzman, Tokihiko Kobata, Editorial to selected papers from the 5th International Conference IMEKO TC16, Acta IMEKO, vol. 7, no. 1, article 11, March 2018, identifier: IMEKO-ACTA-07 (2018)-01-11

Editor: Dušan Agrež, University of LUBLAANA, Slovenia

Received March 29, 2018; In final form March 29, 2018; Published March 2018

Copyright: @ 2018 IMEKO. This is an open-access article distributed under the terms of the Creative Commons Attribution 3.0 License, which permits unrestricted use, distribution, and reproduction in any medium, provided the original author and source are credited

Corresponding author: Jorge C. Torres-Guzman, e-mail: jorge.torres@cenam.mx

\section{INTRODUCTION}

This section is centred on the $5^{\text {th }}$ International Conference IMEKO TC16 which was held in the city of Pereira, Colombia on May 2017. The conference was performed in conjunction with the $6^{\text {th }}$ International Conference of the CCM WG Pressure and Vacuum. The National Institute of Metrology (INM) Colombia organized these conferences.

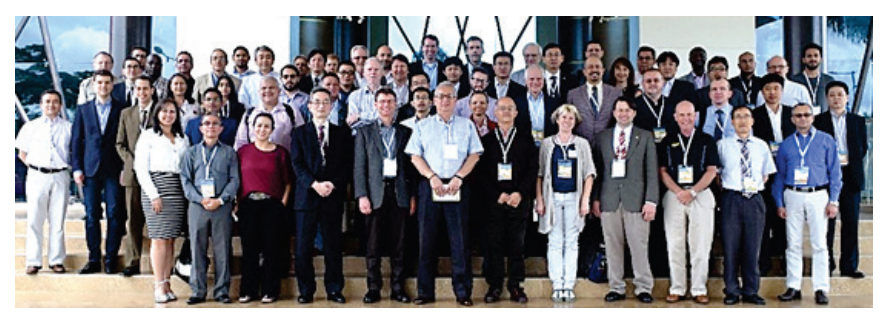

The main objectives of these scientific events and contributions were to present the latest research, to stimulate information exchanges on current activities dedicated to the measurement, calibration and development of pressure and vacuum. The members of the IMEKO TC16 Board identified 8 valuable contributions presented in the Pereira events, for eventual publication in ACTA IMEKO. Their authors were invited to submit extended and updated versions of their selected papers. All of the authors that gave positive responses to this challenge started sending their extended papers to the ACTA IMEKO online submission system at middle of 2017. A great team of reviewers proceeded in successive stages, their task of assessing the papers and submitting their recommendations. The final list of 6 published papers in this issue is a high-quality exhibit of the papers submitted to our Conferences. All the reviewers involved in the process contributed to improve the shape as much as the intrinsic content of the papers.

We invite you to continue and increase your partnership with ACTA IMEKO in all levels.

\section{ABOUT TC16}

The realization of the pressure scale comprises 18 decades, from $10^{-9} \mathrm{~Pa}$ to $10^{9} \mathrm{~Pa}$, this is one of the reasons for which the applications of pressure measurement technology reach into many fields. One example is at the process industry, where all types of manometers and transmitters are found, to measure absolute, gauge and differential pressure. These devices are not only used for the measurement of pressure, but also to control the process. Practice shows that there is an increasing need to carry out international work to homogenize criteria, procedures and uncertainty evaluation to facilitate technical information exchange; to develop projects among groups from different nations; and to support measurements and calibrations for mutual recognition between country's National Metrology Institutes or Accreditation Bodies. This Technical Committee pursues this goal by the organization of different activities. The current members of TC16 are:

\begin{tabular}{|c|c|}
\hline Dr. Tokihiko Kobata, Chairperson & Japan \\
\hline Dr. Jay H. Hendricks, Vice Chairperson & USA \\
\hline $\begin{array}{l}\text { Dr. María Nieves Medina Martin, Scientific } \\
\text { Secretary }\end{array}$ & Spain \\
\hline Dr. Dominik Prazak, Scientific Secretary & Czech Republic \\
\hline $\begin{array}{l}\text { Dr. Jorge C. Torres-Guzman, Advisor (Past } \\
\text { Chairman) }\end{array}$ & Mexico \\
\hline
\end{tabular}




\begin{tabular}{|c|c|}
\hline Dr. Sam-Yong Woo & Republic of Korea \\
\hline Dr. A. K. Bandyopadhyay & India \\
\hline Prof. Giorgio Buonanno & Italy \\
\hline Dr. Anita Calcatelli & Italy \\
\hline Dr. Marcello Caravaggio & Italy \\
\hline Mr. Tawat Changpan & Thailand \\
\hline Mr. Michael D. Collins & United Kingdom \\
\hline Mr. Alexandre Filipe da Silva Lourenco & Portugal \\
\hline Dr. Alaa El-Din A. E. El-Tawil & Egypt \\
\hline Dr. Peter Farar & Slovakia \\
\hline Dr. John Greenwood & United Kingdom \\
\hline Dr. Seung-Soo Hong & Republic of Korea \\
\hline Dr. Karl Jousten & Germany \\
\hline Dr. Rifat Kangi & Turkey \\
\hline Dr. Alper Elkatmis & Turkey \\
\hline Dr. Yasin Durgut & Turkey \\
\hline Dr. Jean-Claude Legras & France \\
\hline Dr. Gianfranco Molinar & Italy \\
\hline Dr. Akira Ooiwa & Japan \\
\hline Mr. Luiz Hemrique Paraguassu & Brazil \\
\hline Dr. Wladimir Sabuga & Germany \\
\hline Dr. Marina Sardi & Italy \\
\hline Dr. Janez Setina & Slovenia \\
\hline Mr. Schalk Smit & South Africa \\
\hline Brian Yalisi & South Africa \\
\hline Dr. Jiri Tesar & Czech Republic \\
\hline Mr. Jos C. G. A. Verbeek & The Netherlands \\
\hline Dr. Christian Wuthrich & Switzerland \\
\hline Dr. Martin Wuest & Liechtenstein \\
\hline Mr. Alvaro Bermudez Coronel & Colombia \\
\hline Mr. Mayckol J. Morales Castro & Colombia \\
\hline Mr. Pengcheng Zhang & China \\
\hline Prof. Davor Zvizdic & Croatia \\
\hline Dr. Kenta Arai & Japan \\
\hline
\end{tabular}

\begin{tabular}{|l|l|}
\hline Dr. Chris Sutton & New Zealand \\
\hline Ms. Yanhua Li & China \\
\hline Dr. In-Mook Choi & Republic of Korea \\
\hline Mr. Pierre Otal & France \\
\hline Dr. Fredrik Arrhen & Sweden \\
\hline Mr. Hideaki lizumi & Japan \\
\hline Dr. Hiroaki Kajikawa & Japan \\
\hline Mr. Martin Girard & USA \\
\hline Mr. Michael Bair & USA \\
\hline Mr. Jacob Ricker & USA \\
\hline Dr. James A. Fedchak & USA \\
\hline Mrs. Julia Scherschlight & USA \\
\hline Mr. Aykurt Altintas & Denmark \\
\hline Mr. Ambrose Okoth & Kenya \\
\hline Mrs. Sari Saxholm & Finland \\
\hline
\end{tabular}

\section{THE PAPERS}

The papers included in this special section range from vacuum to high pressure, including barometric pressure. In addition, the papers present work performed experimentally as well as analytically. It is also important to note that their applications are at industrial level and at national metrology institute level.

We sincerely hope that all the contributions you will find in the next pages provide you with up-to-date information of your interest.

\section{CONCLUSIONS}

It was an honour for us to act as Guest Editors for a section of ACTA IMEKO, from the perspective of working for a highprofile scientific journal and to promote TC16's activities.

We have to highlight the quality and great flexibility of the electronic submission platform, the most valuable improvement recommendations and comments of the reviewers, the elevated standards for copyediting, proofreading and layout editing services of ACTA IMEKO.

We want to express our deepest gratitude and appreciation to the two Editors in Chief that work very hard to make this section possible, Prof. Paul P. L. Regtien and Prof. Dušan Agrež. 